\title{
CORRELATION OF IMPACTED MANDIBULAR THIRD MOLAR WITH INCIDENCE OF IPSILATERAL ANGLE AND CONDYLAR FRACTURES IN MANDIBULAR TRAUMA
}

\author{
Syed Yasir Ali Abidi, Adnan Babar, Kaleem Ullah Niazi, Ali Akhtar Khan, Atiqa Maryam, Nazish Rasheed \\ Armed Forces Institute of Dentistry/National University of Medical Sciences (NUMS) Rawalpindi Pakistan
}

\begin{abstract}
Objective: To evaluate association of impacted lower third molars with incidence of ipsilateral mandibular angle and condylar fractures.

Study Design: Comparative cross sectional study.

Place and Duration of Study: Maxillofacial Surgery, Department Armed Forces Institute of Dentistry, from Jan 2019 to Dec 2019.

Methodology: Patients reporting to Armed Forces Institute of Dentistry Maxillofacial Surgery Department OPD were diagnosed on the basis of history, clinical signs and symptoms and radiological examinations were categorized as mandibular angle and condylar fractures and impacted lower third molars. A total number of 234 radiographs of patients were examined.

Results: Out of total sample size of 234 patients, 79 (70\%) patients had mandibular angle fractures out of 112 patients that had impacted lower third molars and $80(65 \%)$ patients had mandibular condylar fractures out of 122 patients that did not have impacted lower third molars (122 patients). Statistically significant $p<0.001$ showed positive correlation of impacted mandibular third molars to cause ipsilateral mandibular angle fractures and indirectly preventing condylar fractures.

Conclusion: Common practice for prophylactic removal of lower third molars should be discontinued as impactted third molars, although increases risk of mandibular angle fracture, but indirectly decreases risk postoperative risks and morbidity.
\end{abstract}

Keywords: Impacted mandibular third molars, Mandibular angle fracture, Mandibular condylar fracture.

This is an Open Access article distributed under the terms of the Creative Commons Attribution License (http://creativecommons.org/licenses/by/4.0), which permits unrestricted use, distribution, and reproduction in any medium, provided the original work is properly cited.

\section{INTRODUCTION}

Mandible is exposed to trauma since the days of Adam, while the high-speed travel in modern life along with increasingly violent and intolerant society has made facial trauma a form of social disease from which no one is immune ${ }^{1}$. Mandible is often involved in facial trauma as it is a prominent bone of face leading to fracture. Mandibular fractures account for 15.5-59\% of all facial fractures ${ }^{2}$. Among the facial bone fractures, fracture of condyle is one of the commonest sites with an overall incidence of $18 \%$ to $57 \%$, and incidence of $24 \%$ to $72 \%$ in children ${ }^{3}$. Relatively weaker structure of the neck of condyle makes it a susceptible area to fracture in face of trauma to the mandible and considered as a protective mechanism to prevent fracture of

Correspondence: Dr Syed Yasir Ali Abidi, Department of Oral \& Maxillofacial Surgery, AFID Rawalpindi Pakistan

Received: 02 Apr 2020; revised received: 13 Apr 2020; accepted: 17 Apr 2020 base of skull.

Fractures at angle region comprise $25 \%$ of all mandibular fractures because of weakness due to thin bone, curvature of trajectories due to change from horizontal to vertical rami \& third molars decreasing bone content at the area ${ }^{4}$. Third molars are more commonly found to be impacted due to the modern dietary habits, lack of fibrous diets, hereditary, embryological and other etiological factos 5 . As impacted third molars are considered useless in mouth, most authors recommend their extractions even in absence of pathology. Literature also supports role of impacted third molars in increasing susceptibility of angle area to fractures by weakening it and hence recommending its extraction 6 . However greater incidence of condylar fractures is reported in literature in those patients who do not have impacted lower third molars ${ }^{7}$. Closed and open reduction and internal fixation; both methods have been 
advocated in literature for treatment of condylar fractures depending upon different indications ${ }^{8}$ however both are associated with significant untoward effects and risks. Closed reduction requires use of intermaxillary fixation, depriving the patient of normal functioning of jaw for extended period of time and open reduction has significant risk of damaging branches of facial nerve while obtaining access to condyle. Because of these associated risks and morbidity, surgeons would prefer managing angle fractures as compared to condylar fractures and hence prophylactic removal of impacted third molars is discouraged as their presence can prove to be condylar fracture sparing factor by making angle area more susceptible to fracture in case of trauma. This study will provide the basis to evaluate the practice of prophylactic removal of impacted third molars as it determines the frequency of condylar fractures and angle fractures in association with presence and absence of Impacted lower third molars.

\section{METHODOLOGY}

This comparative cross sectional study was conducted in Armed Forces Institute of Dentistry (AFID) from January 2019 to Decemer 2019. The current study design and protocol was approved from the ethics committee of the AFID 95/Trg/ ABP1K2. All the patients who reported to AFID maxillofacial surgery department with history of facial trauma were examined clinically \& radiographically. Patients with age range 18-55 years and with isolated fractures of mandible were included in the study using consecutive nonrandom sampling technique. Patients with multiple fractures involving bones other than mandible were excluded from study. Sample size was calculated using WHO sample size calculator based on results of study performed by Duan et al ${ }^{9}$. For sample size calculation the level of significance was 0.05 , power of test was $95 \%$, Anticipated population proportion 1 was $51 \%$, anticipated population proportion 2 was $36 \%$, total sample size calculated for the study was 234 patients.
Diagnosis of fracture sites was made by clinical examination and panoramic radiograph. Sites involving the fractures as dentoalveolar, symphysis, parasymphysis, body, angle and condyle and sides of face involved (right or left) were noted for each fracture. Angle fracture was also classified as displaced or non-displaced and sites of condylar fracture was also noted as high condylar neck, low condylar neck and subcondylar fractures. Condylar fractures were also identified as displaced, dislocated or deviated. Panoramic radiograph was assessed to identify whether impacted third molar is present or not at side of face presenting condylar or angle fracture and then identifying its classification based onangulation of impacted third molar to long axis of second molaras mesioangular, vertical, horizontal and distoangular impaction, relationship to Ramus as class I, class II and class III and vertical position of impacted third molar in relation to occlusal level of second molar as class A, class B and class $\mathrm{C}$.

Data was analyzed using statistical software SPSS version 17.1. Descriptive statistics were used to analyze qualitative and quantitative variables. Quantitative variables like age was measured as mean \pm Standard deviation (SD). Qualitative variables like gender, angle and condylar fractures and impacted third molars along with types were measured as frequency and percentages. Chi-square test was applied to compare qualitative variables like gender, angle and condylar fractures and impacted third molars along with types. Independent sample t-test (student t-test) was applied to compare age with impacted third molars, angle and condylar frac-tures. A $p$ value $\leq 0.05$ was considered significant. Statistics and data evaluation (calculated by SPSS).

\section{RESULTS}

Mean ages of patients with impacted third molars was $30.2 \pm 6.1$ years, without impacted third molars was $32.1 \pm 9$, with angle fracture was $30.2 \pm 6.6$, without angle fracture was $32.1 \pm 8.8$, with condylar fracture was $32.3 \pm 8.8$ and without condylar fracture was $30.1 \pm 6.6$. A $p<0.05$ was 
statistically significant. Among 112 patients having impacted third molars, $79(70 \%)$ were males and $33(30 \%)$ were females. Among males, mandibular angle fractures were slightly more common than mandibular condylar fractures however among females, mandibular condylar fractu- suffered from mandibular angle fractures. A $p$ value came out to be $<0.001$ (table-II). Mandibular angle fractures were more com-monly associated with partially impacted third molars with higher occlusal levels i.e. $81 \%$ class I impacted third molars and $77 \%$ Level A impacted third molars

Table-I: Grouping of variables according to impacted mandibular third molars, mandibular angle fracture and condylar fracture.

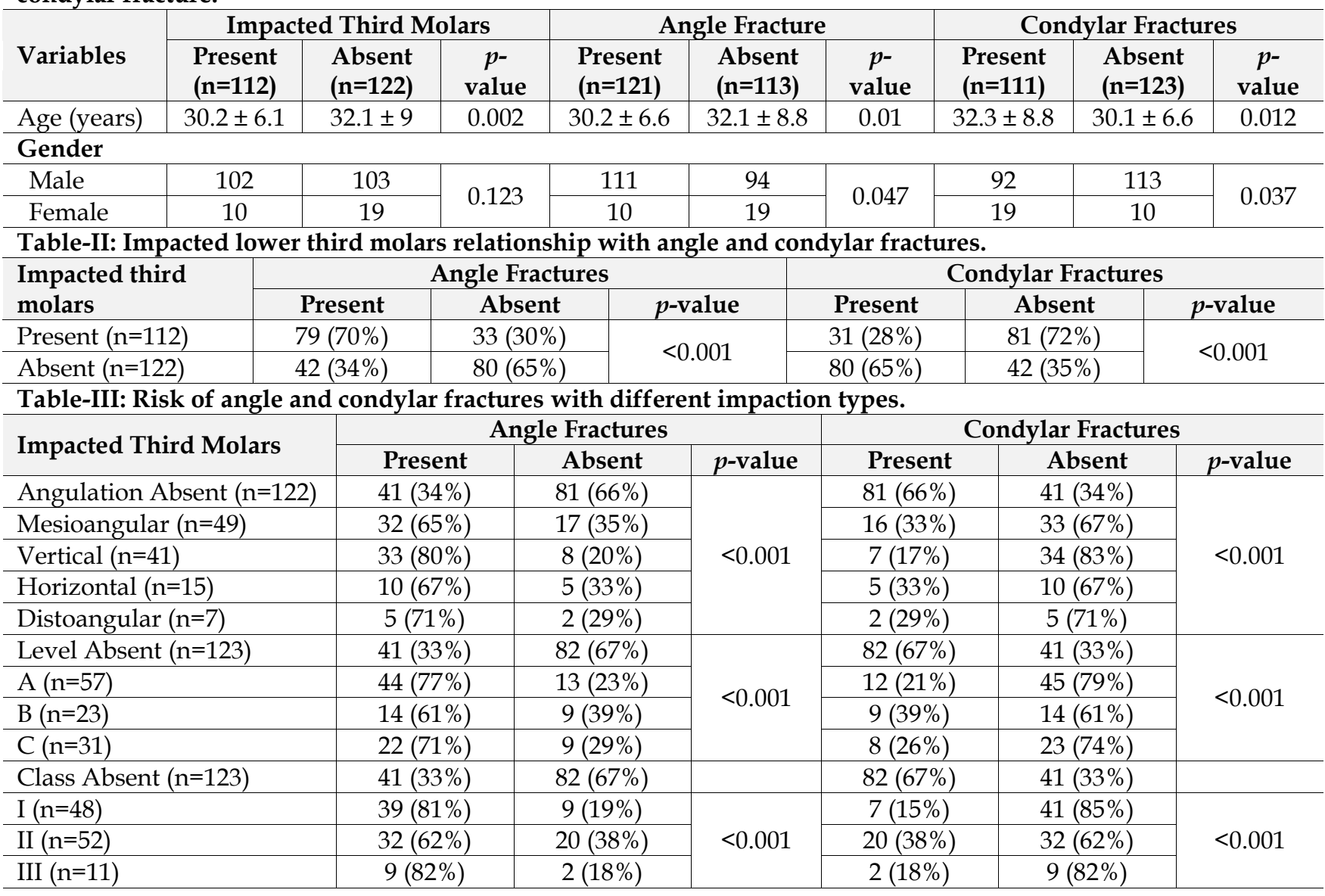

res were more common than mandibular angle fractures. A $p<0.001$ was statistically significant (table-I).

Seventy nine out of 112 patients (70\%) with impacted lower third molars suffered from mandibular angle fractures at site of impaction. Only 31 out 112 patients (28\%) with impacted third molars suffered condylar fractures of ipsilateral side. Eighty out of 122 patients (65\%) that did not have impacted third molars suffered from condylar fractures whereas only 42 out of 122 patients (34\%) that did not have impacted third molars were associated with mandibular angle fractures (table-III).

\section{DISCUSSION}

Various factors are responsible for mandibular fractures including type of injury, force and direction of injury and strength of the bone. Angle and condyle areas are most commonly involved sites of fractures in case to trauma. Kelly \& Harrigan ${ }^{10}$ defines mandibular angle fracture as loss of continuity in bone present posterior to second molar on a concave area formed by union of ramus and body in retromolar region, exten- 
ding curvy area formed at inferior border of mandible by fusion of body and posterior border of ramus and defines condylar fracture as break in bony continuity superior to sigmoid notch ${ }^{10}$.

Various classifications are used for impacted mandibular third molars such as based on angulation of impacted third molars to long axis of second molars as mesioangular, distoangular, vertical and horizontal ${ }^{11}$, Pell \& Gregory ${ }^{12}$ classifications based on relation of impacted third molars with Ramus as class I with third molar completely anterior to Ramus, class II with third molar partially covered by Ramus and class III with third molar fully covered by Ramus \& Pell \& Gregory classification based on vertical relationship of impacted third molars with occlusal level of second molar as class A with third molar at same occlusal level as that of second molar, class B with third molar below occlusal level of second molar but above the alveolar ridge and class $C$ with third molar within the alveolar ridge $^{12}$. In case of mandibular trauma, forces of tension are generated at the superior border of mandibular angle area and compression forces are generated at the lower border. These forces of tension coupled with loss of the cortical strength by presence of mandibular impacted third molars decrease the strength of mandible at angle area by decreasing the amount of bone especially at the superior border, making this area susceptible to getting fractured and indirectly sparing mandibular condyle from getting fractured ${ }^{12}$. Superior positioning of impacted third molars like class A \& B is supposed to make mandibular angle area particularly more susceptible to fractures as reported in various researches in literature ${ }^{13}$. The results of this study are consistent with this finding as $77 \%$ were impacted third molars with level A vertical position were found associated with mandibular angle fractures. One retrospective study done by Mah et al ${ }^{12}$ on mandibular fracturesin 440 patients showed that mandibular angle fractures occur more commonly in patients with mandibular third molar in a ratio of 1.26:1 that is statistically significant and mandibular condylar fractures correlation with impacted mandibular third molar is statistically less significant ${ }^{14}$. A study conducted by Zhu et al ${ }^{15}$ reported that risk of condylar fractures rises to 3.5 times higher when a patient has missing impacted third molars as compared to patients that have impacted third molars. Risk was found to be 2.5 times higher for condylar fractures in patients with impacted third molars as compared to those without impacted third molars by Thangavelu ${ }^{16}$, Shah et al17 reported risk of suffering from condylar fractures reduces by 2.2 times when an impacted third molar is present. Duan et al ${ }^{9}$ evaluated the association of impacted third molars with mandibular angle and condylar fractures and found that condylar fractures were present in $51 \%$ patients that had missing impacted third molars as compared to $36 \%$ patients in which impacted third molars were present and angle fractures were found in only $14 \%$ patients in which impacted third molars were absent as compared to $41 \%$ in which impacted third molars were present ${ }^{17}$. Treatment of condylar fracture is still controversial and debatable, choice of selecting open or closed reduction depend upon various factors including age and growth, type of fracture, degree of displacement, status of occlu$\operatorname{sion}^{18}$ and open reduction of condylar fracture can cause serious complications including facial nerve injury ${ }^{19}$. Even when closed reduction is performed, prolonged period of intermaxillary fixation have adverse effects on quality of patient's life $^{20}$. Furthermore, open reduction of condylar fracture is very technique sensitive procedure as it is highly difficult to perform accurate reduction of condylar fragments and place plates and screws maintaining accurate condylar fragments reduction ${ }^{21}$ and simultaneously correct occlusion. On the other hand, accurate reduction and fixation of mandibular angle fracture is comparatively easier owing to greater access and visibility to fix the plates at angle area. Considering the complications that can be associated with condylar fracture and in light of literature, it is suggested that practice of prophylactically removing impacted third molars should be discontinued as missing third molars can increase risk of 
condylar fractures 2.2 to 3.5 times as reported in literature.

This study has highlighted the fact that the impacted third molars make angle area significantly susceptible to undergo fracture in case of mandibular trauma. Weakening of superior border of mandible is most critical factor in increased risk of angle fractures that was suggested by increased incidence of mandibular angle fractures associated with level A impacted third molars. This can be explained by the fact that higher level of impaction reduces the amount of bone at the superior border of mandibular angle.

\section{CONCLUSION}

Common practice for prophylactic removal of lower third molars should be discontinued as impacted third molars, although increases risk of mandibular angle fracture, but indirectly decreases risk postoperative risks and morbidity.

\section{CONFLICT OF INTEREST}

This study has no conflict of interest to be declared by any author.

\section{REFERENCES}

1. Garkoti PD, Saklani K, Shashi, Sharma T. A study on incidence of mandibular fractures in cases of faciomaxillary trauma in kumaon region. J Evol Med Dent Sci 2015; 4(72): 12581-86.

2. Vyas A, Mazumdar U, Khan F, Mehra M, Parihar L, Purohit C. A study of mandibular fractures over a 5-year period of time: A retrospective study. Contemp Clin Dent 2014; 5(4): 452-55.

3. Kuang SJ, He YQ, Zheng YH, Zhang ZG. Open reduction and internal fixation of mandibular condylar fractures. Medicine (Baltimore) 2019; 98(37): 1-8.

4. Basheer-Rehman, Iqbal A, Afsar H, ud Din Q, Ansari SR. Comparative analysis of extraoral and intraoral approaches in mandibular angle fracture. J Khyber Coll Dent 2015; 5(2): 16-19.

5. Inaoka SD, Carneiro SCAS, Vasconcelos BCE, Leal J, Porto GG. Relationship between mandibular fracture and impacted lower third molar. Med Oral Patol Oral Cir Bucal 2009; 14(7): 349-54.

6. Duarte BG, Assis D, Ribeiro-Júnior P, Gonçales ES. Does the relationship between retained mandibular third molar and mandibular angle fracture exist? an assessment of three possible causes. Craniomaxillofac Trauma Reconstr 2012; 5(03): 127-36.
7. Adeyemo $\mathrm{WL}$, Ladeinde $\mathrm{AL}$, Ogunlewe MMO. Prophylactic surgical removal of impacted third molars: contemporary views. Common risk factors for postoperative pain following the extraction of wisdom teeth. Pak OralDent 2005; 25(1): 11-14.

8. Neff A. Open reduction and internal fixation in temporomandibular joint traumatology: current concepts and future perspectives. Stomatological Dis Sci 2019; 3(1): 1-14.

9. Duan DH, Zhang Y. Does the presence of mandibular third molars increase the risk of angle fracture and simultaneously decrease the risk of condylar fracture? Int J Oral Maxillofac Surg 2008; 37(1): 25-28.

10. Kelly D, Harrigan W. A survey of facial fractures related to teeth and edentulous regions. J Oral Surg 1975; 33(1): 146-49.

11. Alfergani SM, Latif K, Alanazi YM. Pattern of impacted mandibular third molars in a Saudi population. Pak Oral Dental J 2017; 37(3): 408

12. Hasegawa T, Sadakane H, Kobayashi M, Tachibana A, Oko T, Ishida $\mathrm{Y}$ et al. A multi-centre retrospective study of mandibular fractures: do occlusal support and the mandibular third molar affect mandibular angle and condylar fractures? Int J Oral Maxillofac Surg 2016; 45(9): 1095-99.

13. Nogami S, Yamauchi K, Bottini GB, Kouketsu A, Otake Y, Sai Y, et al. Do mandibular third molars play a role in fractures of themandibular angle and condyle? J Craniofac Surg 2018; 29 (29): e713-17.

14. Mah DH, Kim SG, Moon SY, Oh JS, You JS. Relationship between mandibular condyle and angle fractures and presence of mandibular third molars. J Korean Assoc Oral Maxillofac Surg 2015; 41(1): 3-10.

15. Zhu SJ, Choi BH, Kim HJ, Park WS, Huh JY, Jung JH, et al. Relationship between the presence of unerupted mandibular third molars and fractures of the mandibular condyle. Int J Oral Maxillofac Surg 2005; 34(4): 382-85.

16. Thangavelu A, Yoganandha R, Vaidhyanathan A. Impact of impacted mandibular third molars in mandibular angle and condylar fractures. Int J Oral Maxillofac Surg 2010; 39(2): 136-39.

17. Shah SMH, Shad S, Hameed H, Abbassi MM. Role of mandibular third molar in mandibular condylar fracture. Pak Oral Dent J 2018; 38(1): 34-37.

18. Khan S, Khan A, Saifullah MT, Syed K, Sohail M, Shah SA, et al. Pattern of condyalr fractures and its treatment in tertiary care hospital-a study. J Khyber Coll Dent 2019; 9(1): 43-7.

19. Nayak SS, Kamath AT. Surgical management of double/triple mandibular fractures involving the condylar segment: Our perspective. J Int Soc Prev Community Dent 2018; 8(1): 87-89.

20. Braimah RO, Ukpong DI, Ndukwe KC, Akinyoola AL. Healthrelated quality of life in Nigerian patients following maxillofacial and orthopedic injuries: A comparative study. J Orthop Trauma Rehabilitation 2018; 10(1): 49-53.

21. Gali R, Devireddy SK, Venkata KK, Kanubaddy SR, Nemaly C, Dasari M. Preauricular transmasseteric anteroparotid approach for extracorporeal fixation of mandibular condyle fractures. Indian J Plast Surg 2016; 49(1): 59-65. 